\title{
Preparation of Low Rolling Resistance Modified Asphalt and Analysis of Its Rolling Resistance and Viscoelasticity
}

\author{
Haibin LI*, Mingming Zhang, Wenbo LI, Yan LI, Qinwei MA, Guijuan ZHAO
}

\begin{abstract}
Tire tread of running vehicles generates rolling resistance with the pavement, thereby influencing energy consumption. Thus, developing low rolling resistance pavement can improve the service function of tires. Common matrix asphalt and high module binder modifier (HMB-W) was used to obtain low rolling resistance of asphalt and effectively reduce energy consumption. Its low rolling resistance performance was analyzed via internal heat-generating test, rolling resistance test, and dynamic shear rheological test. Then, a rolling resistance model was constructed to evaluate its thermal losses. Test results show that compared with stvrene-butadiene-styrene (SBS) modified asphalt and its mastic, the heat generation rates of HMB-W modified asphalt and its mastic are reduced by $14.4 \%$ and $15.5 \%$ upu be effectively reduced. The generated heat quantity and power loss were reduced by $3.7 \%$ and $5 \%$, respectively, compared with th $\Delta S$ modifieu phalt. In addition, the low rolling resistance is evident. HMB-W asphalt has low-temperature sensitivity and superior high-temperature stability. Under same stress lev the complex shear module $G^{*}$ of HMB-W asphalt is evidently higher than that of SBS modified asphalt. Under the same temperature condition, the ent stored is high goes through elastic deformation with small viscosity loss.

Keywords: low rolling resistance modified asphalt; low rolling resistance model; pavement engineering; rolling resis ce; viscoe' ticity
\end{abstract}

\section{INTRODUCTION}

Polymer modified asphalt is generally applied to existing asphalt pavement to improve the damage resistance. However, under the action of repeated load, dynamic heat generation occurs inside the modified asphalt due to the mechanical energy of vehicle load. As the temperature rises, the elasticity modulus of asphalt material is reduced, whereas the loss modulus is incre. Especially during summer, at high temperature, elasticity loss of modified asphalt materials with high he generation rate is serious. Viscous remarkably increased with easy flow and cforma $n$, and aggregate particles experience disp emen forming permanent deformation [ 17 redu che internal heat-generating degree of mod d asphalt the key to relieving rutting problems of pha vavement. - 2 use of low rolling resistance payement gen tes a far-reaching effect on reducing ener consumption. ssent studies on low rolling resistar main' focus on the tire field. Specifically, rubbe ires a modified through molecular structural design, and rubber h low dynamic heat generation acquing by reducing its strain hy resis $b$,ed on a neory of viscoelasticity to produce w roll tires. The studies on tires are mainly bas the principle of rheology [2].

Damages asphalt pavement, such as rutting, fatigue, and cracking, ar jirectly related to rheological properties and viscoelasticity of asphalt [3]. Rheology is a science studying flow and deformation of time and temperaturedependent materials. In general, asphalt rheology is a science characterizing asphalt flow and deformation, including the determination and calculation of a series of asphalt viscoelasticity indexes. The studies on rolling resistance of asphalt pavement, which is the most extensively applied pavement, are still in the preliminary stage. Generally, damping characteristics and parameters of polymer materials are used to characterize the materials' ability to dissipate mechanical energy in the form of heat. This index can reflect the motion behaviour caused when the materials impede mechanical energy; it can also be used to $c^{\prime}$ acterize th ner dissipation degree of the polym ma ials under th cyclic loading action [4]. On a pavement, 2. of the resistance borne by a running results fro rolling frictional resistance; it is the power consumed by the moment of force generated by tire and paver nt deformations. Pavement deformation onsists of asphalt material and pavement structural 'ormatir s, which are dissipated by the mechanical energ, of vehicle load in the form of internal heat neration of the material. The strain delay and energy loss of the asphalt material under sine alternating tensile stress load are primary factors leading to damping [5].

On this basis, a type of low rolling resistance asphalt was studied and developed. Its rolling resistance and elasticity were analyzed by combining internal heatgenerating test. In addition, rolling resistance test and viscoelasticity test, and a rolling resistance model used to evaluate heat loss were constructed to lay a foundation for further exploring the pavement performance of its mixture.

\section{STATE OF THE ART}

When a vehicle is normally running on the pavement, its tires experience rolling on the pavement surface. The central symmetrical plane of tire outer edges is consistent with the rolling direction, the resistance opposite to the rolling direction is called tire rolling resistance, and the rolling resistance consists of tire deformation caused by pavement extrusion, pavement deformation occurring under loading action and tire-pavement reverse friction [68]. On the basis of truck fuel consumption, measurement of tire rolling resistance, and verified modelling via business software AVL-CRUISE, Laclair and Russell et al. [9-11] found that automobile fuel consumption could be saved by $4.77 \mathrm{lt} / 100 \mathrm{~km}$ on a secondary road and by 5.49 $1 \mathrm{t} / 100 \mathrm{~km}$ on the expressway when the rolling resistance was reduced by $1 \mathrm{kN}$. Present studies on regarding low rolling resistance pavement mainly focus on rubber tire field. Strain hysteresis of rubber is reduced, and low rolling resistance tires are produced based on the mechanical theory of viscoelasticity $[12,13]$. For vehicles without a 
suspension system, Wang [14] established a radial spring tire-ground contact model, the time-domain model of filtered white noise pavement roughness, and energy loss model in the vehicle wheel vacant process. Then, he analyzed the energy loss caused by the wheel passing through an uneven road surface. For axle load, Jaime A. Hernandez [15] calculated the rolling resistance based on three values, namely, tire inflation pressure, temperature, and velocity. He proposed a mathematical expression via regression analysis, so as to predict the rolling resistance encountered by tires running on pavements, considering these variables.

Asphalt pavement is the most extensively applied road surface. Reducing energy consumption of pavement by investigating low rolling resistance modified asphalt has been the focus of emerging research fields on asphalt materials. $\mathrm{Bi}$ [16] investigated and developed low rolling resistance asphalt modifier HPT and determined the influence of different adulterate amounts on conventional indexes of modified asphalt through a series of tests. The study results showed that as the adulterate amount of HPT increased, the softening point of modified asphalt was elevated, the penetration and ductility were reduced, the viscosity was strengthened, the segregation characteristic was effectively improved, and the non-uniform dispersion phenomenon generated by SBS under high-temperature condition was relieved. Thus, SBS formed a net structure, and its performance was enhanced. If the low rolling resistance asphalt was standardized according to the I-D standard of SBS modified asphalt, then the adulterate amount of its low rolling resistance modifier HPT woul be within $0.25 \%-1.62 \%$. Espinoza-Lque [17] probed the laboratory performance of two low rolling romictance modified asphalt mixtures specially designed Den ark Road Bureau and explored their effects on $r$ acing $r$ ing resistance and tested their dynamic modulus, The c onm. and rutting possibilities of the mixture were el ated via Illinois flexibility index test and $\mathrm{Hz}$ "rg wheel t. $\mathrm{k}$ test, respectively. They found that low olling resis ince modified asphalt mixture ith low ro ng resistance presented low modulus y ar low tempera modulus under high te erature thad higher flexibility index $(F I)$ and lower arm deformation than the matrix asphalt miyture.

At present cho s hav tar studying the rolling resistance $0^{f}$ sphalt $\mathrm{p}$ terials. $\mathrm{w}$ wever, some researchers have invest ted characteristics of asphalt materials. Dan g is the degree of energy loss of asphalt material under lo. ing action, and stress-strain hysteresis is the internal cause or energy loss. Greater stress-strain hysteresis causes larger damping and energy loss, and smaller stress-strain hysteresis indicates smaller damping and energy loss [18-22]. Biligiri [23, 24] studied the damping characteristics of different pavements, collected and analyzed massive data through tests, obtained physical parameter damping of asphalt material and established the relation between phase angle and noise of pavement materials. Zhang [25] attempted to develop low-damping modified asphalt to reduce rolling resistance and internal heat generation during the automobile running process and to solve problems, such as fuel consumption and pavement damage. He also introduced loss factor, which characterized fuel consumption during automobile tire running process, into asphalt to characterize the internal heat generation and mechanical loss of asphalt materials. Four polymers with different molecular structures were selected as modifiers and combined with SBS to prepare low-damping modified asphalt. Polymer modifiers were selected through loss factor and complex modulus. The results of internal heat-generating test and rolling resistance test showed that the low-damping modifier could reduce power loss and internal heat generation of SBS modified asphalt. A microstructure analysis showed that the low-damping modifier enlarged the swelling area of the SBS phase. Thus, more light components in asphalt could fill into the SBS phase to increase the elasticity modulus of modified asphalt and reduce the internal heat generation. The results of the curren low rolling resistance modified asphalt ho mainly volved the influence of the adulterate amou of low rollin resistance modifier on the perform ce on sphalt a mixture. However, few studi have ph ed ato asphalt viscoelasticity.

To tackle the den anc of the existing studies, the analysis idea colling istance id viscoelasticity of asphalt was ed, that is, on self-developed low rolling re, sanco odified as malt, four different asphalt types, namely, HM W asphalt, SBS modified asphalt, HY mineral po der, and SBS modified asphalt + $\mathrm{m}$ eral powder were prepared. Then, internal heat$\mathrm{g}$ erating test ad rolling resistance test were conducted. In cordance y theological theory of pavement asphalt mato and material viscoelasticity test method, the difference between low rolling resistance modified asphalt c. MS modified asphalt in terms of rheological properties was analyzed.

The remainder of this study is arranged as follows: Section 3 explains the related test materials and analysis method of the rolling resistance and viscoelasticity. Section 4 presents the result analysis of internal heatgenerating test, rolling resistance test, and temperature sensitivity test. The final section summarizes the whole study and provides related conclusions.

\section{METHODOLOGY}

\subsection{Preparation of the Low Rolling Resistance Modified Asphalt}

The low rolling resistance asphalt pavement mainly modifies the rubber on the precondition of vehicle safety to relieve strain hysteresis of rubber tire and reduce the rolling resistance between the tire and the pavement. Therefore, the low rolling resistance asphalt modifies the asphalt through a certain method to mitigate pavement deformation and strain hysteresis to reduce rolling resistance. Asphalt, as common road material, has certain viscoelasticity. Asphalt is modified using several approaches to elevate the modulus of asphalt mixture and reduce the elastic deformation of pavement, its strain hysteresis is an effective means to realize low rolling resistance performance of asphalt pavement.

Hard asphalt with low penetration is considered low rolling resistance asphalt binder to elevate mixture modulus. With zero penetration and high softening point, natural asphalt is a superior material used to prepare low rolling resistance asphalt. Raw natural asphalt was selected 
in accordance with asphalt content and composition of four asphalt components and mineral substances of natural asphalt from different places of origin. Its particle size was reduced by unique processing methods. As a result, the surface effect of trichloroethylene undissolved particles became prominent, the specific surface area was enlarged, the surface activity was enhanced, and the particles were dispersed in asphalt through physical actions. Meanwhile, asphalt storage stability was further guaranteed through chemical stabilization. On this basis, a type of low rolling resistance modified asphalt was prepared. The concrete preparation process is presented in the following section.

The low rolling resistance modified asphalt was prepared using dispersing shearing machine and motor stirrer through a blending process. The matrix asphalt was initially heated to above $160{ }^{\circ} \mathrm{C}$ to obtain good fluidity. SBS, HPT, and extract oil were successively added at shear rate of $4000 \mathrm{rpm}$ and temperature of $170-180^{\circ} \mathrm{C}$, and the shearing lasted $45 \mathrm{~min}$. Lastly, the stabilizer was added at $180{ }^{\circ} \mathrm{C}$ and $700 \mathrm{rpm}$ conditions for $150 \mathrm{~min}$ low-speed stirring. Then, low rolling resistance modified asphalt was acquired. In the low rolling resistance modified asphalt, the additive amounts of low rolling resistance modifier (calculated by asphalt mass), SBS, extract oil, and stabilizer were $1.5 \%, 4 \%, 5 \%$, and $0.2 \%$, respectively.

\subsection{Conventional Performance Study on Low Rolling Resistance Modified Asphalt}

The conventional performance indexes of the low rolling resistance modified asphalt, namely, penetration, ductility, softening point, density, and ageing performance were detected in accordance to the test method specified in Standard Test Methods of Bitumen and Bituminous Mixtures for Highway Enginee or E20-2011). The virgin asphalt used in the sty was KLl Pen70 asphalt produced in China. Then, tho results werc ompared with those of the conventi al po rmance dexes of the prepared SBS modif

Table 1 Comparison of low rolling resistance modified asphalt and sphalt

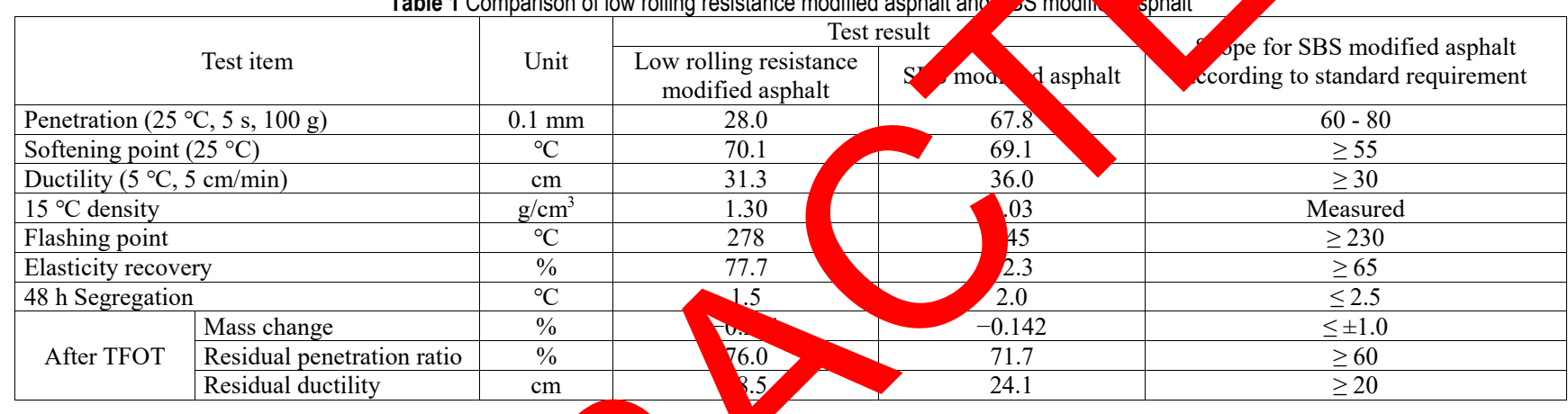

Tab. 1 shows that:

1) The fluidity of the low rolling asphalt was poor and the penetratic than that of SBS modified asphal ecause it processed by modifying hard asphalt low penc tion. In addition, ductility and elasticry reco $\mathrm{v}$ of the low rolling resistance modified asp $\mathrm{r}$ at $5{ }^{\circ} \mathrm{C}$ wer duced relatively when compared wit those of SBS mudified asphalt, probably ascribed the $c^{\prime}$ racteristics of natural hard asphalt; 2) The rison the st-ageing performance
indexes $9^{f}$ an low olling ance modified asphalt and SBS $m$ fied as alt showe that the residual penetration ratio and al ductmy of the low rolling resistance modified asp lt were higher than those of SBS modified asphalt. This ding indicated that the low rolling resistance modifred asphalt had superior anti-ageing performance;

3) The $48 \mathrm{~h}$ segregation test result of the low rolling resistance modified asphalt was better than that of the SBS modified asphalt. This result suggested the favourable storage stability of the low rolling resistance modified asphalt because its main component was natural asphalt, and special processing technology was adopted.

\subsection{Internal Heat-Generating Test Method}

To simulate the effect of aggregate on the low rolling resistance modified asphalt, HMB-W was combined with mineral powder at a proportion of 50:50. Meanwhile, the SBS modified asphalt was combined with mineral powder at a proportion of 50:50, and then asphalt mastic was prepared. The prepared low rolling resistance modified asphalt, SBS modified asphalt, and their mastics were injected into a specially fabricated flexural and compression-type internal heat-generating test die, which was then heated at high temperature. Then, vulcanized flexural and compression-type internal heat-generating test model was used. The specimen was cylindrical with a diameter of $17.8 \mathrm{~mm} \pm 0.15 \mathrm{~mm}$ and height of $25.00 \mathrm{~mm}$ $\pm 0.25 \mathrm{~mm}$.

The stipulated compressive load was applied to the specimen via a balanced lever with high inertia, followed by high-frequency cyclic compression with constant amplitude. The temperature rise at the bottom of the specimen was measured using a thermocouple. This thermocouple could be used to determine heat generation situation of the specimen during the flexing process, and the cycle index was recorded when fatigue failure was generated.

After bearing a constant load, the specimen was initially compressed during the test process and the height change of the specimen was continuously tested. After the test, the permanent compressive deformation of the specimen could be calculated.

The flexural and compression-type internal heatgenerating test model is shown in Fig. 1. 


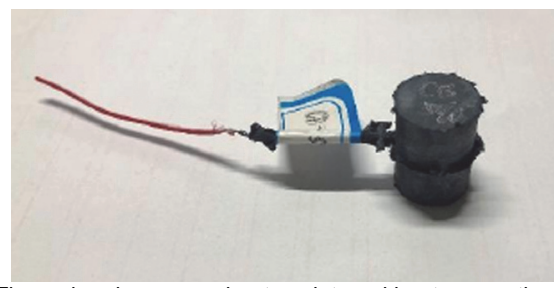

Figure 1 Flexural and compression-type internal heat-generating test model

The specimen was placed between two pressing plates fabricated using heat-insulating materials. The upper pressing plate was connected to an adjustable eccentric gear, and the oscillation frequency was generally $30 \mathrm{~Hz}$ $\pm 0.2 \mathrm{~Hz}$.

The load was applied through a lever placed on the cutter edge. A $24 \mathrm{~kg}$ weight was suspended at each of the two ends of the lever system to reduce the inherent frequency of the lever and to enlarge its rotational inertia. The lower pressing plate moved up and down relative to the lever by adjusting a calibrated vernier device. With reference marks at the pointer and lever ends, the lever system was maintained at a horizontal position during the test process.

The temperature rise at the bottom of the specimen was measured with the thermocouple installed at the center of the lower pressing plate.

\subsection{Rolling Resistance Test Method}

The rubber rolling resistance testing machine is a brand new test instrument designed on the basis of th original Dunlop Rotary Power Loss Machine, following the advanced modular design concept and combining computer technology servo control techno so and infrared temperature measurement technolog The ry ber rolling resistance testing machine is show $q$ Fig. its internal structure is shown in Fig. 3 the 1 and SBS modified asphalt were mixed in carbon bla rubber using a rubber mixing mill (Fig the mixin ratio was $5 \%$ of the mass of carbon black rub

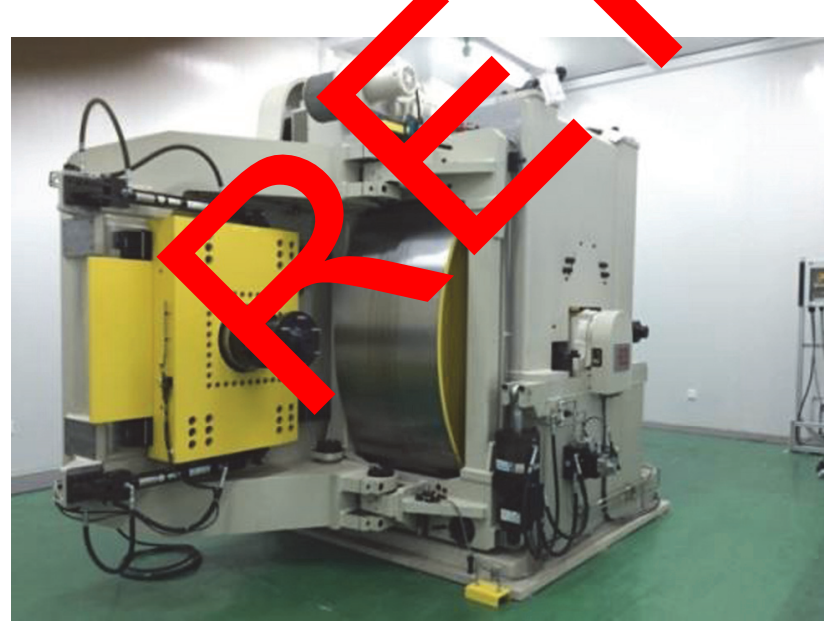

Figure 2 Rubber rolling resistance testing machine

The mixed rubber sample was placed into the die specially fabricated by the rubber rolling resistance testing machine in the rubber vulcanization machine. Then, it was heated at high temperature and vulcanized into a rolling resistance test model (outer diameter: $102 \mathrm{~mm}$, inner diameter: $63.5 \mathrm{~mm}$, and width: $19 \mathrm{~mm}$ ).

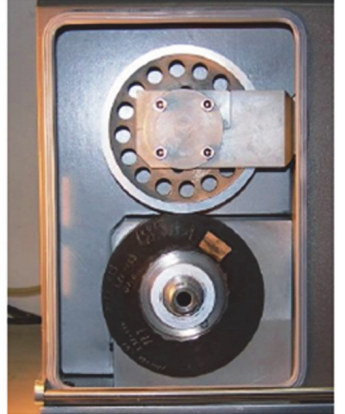

Figure 3 Internal structure of rubber rolling resistance testing machine

The circular wheel-shaped rubber specimen moving at constant speed closely contacted the drum under a given load to obtain a relative oveme The rubber specimen experienced deforme on under the oad. Then, the deformation gradually reach the max hum from point A to point B and gre ally redu do ze from point $\mathrm{B}$ to point $\mathrm{C}$. The for of the $\mathrm{r}^{\wedge}$ ber $\mathrm{s}$,en during the deformation from po A to sint B washigher than that during the recoy $y$ pen $\mathrm{B}$ to point $\mathrm{C}$ due to rubber stress ain action. This ce was parallel to the load force sh same dire namely, the power loss $(\mathrm{J} / \mathrm{r})$ of the rubber ecimen. Then, the rolling resistance coeff could be in her solved. In accordance with the Te Methods of Rolling Resistance for Motor Vehicle $\mathrm{T}$ es, the tw specimens were placed under rolling re stance test ing the rubber rolling resistance testing mau ne.

\section{iscoelasticity Theory and Test Method}

The main method of viscoelasticity analysis is based on a theoretical analysis of test characteristics. The test analysis mainly investigates the dependence of stress and strain to loading rate and sensitivity to temperature. The mechanical behaviour of the viscoelastic material is related to excitation time $(t)$; thus, its stress and strain constitute a function of time. Assuming that the strain $\varepsilon(t)$ of the viscoelastic body at any time $t$ under the action of external force depends on the stress $\sigma(t)$ until this time, the functional relation between stress and strain can be expressed in Eq. (1), as follows:

$\sigma(t)=F_{-\infty}^{t}[\sigma(\tau)]$

Dynamic viscoelasticity refers to the mechanical behaviour and characteristics of a viscoelastic object, as shown under the action of oscillation load (sine wave under normal circumstances); its mechanical property is between elastic solid and viscous fluid. The basic features of dynamic viscoelasticity analysis are small deformation, linear characteristic, time lag (phase difference), and complex number method. The most important parameters are modulus and compliance of complex number. Similar to the definition of elasticity modulus given in Hooke's Law, the ratio of complex stress to complex strain is generally defined as complex modulus in the dynamic viscoelasticity analysis; it is recorded as $R^{*}(i \omega)$. When oscillation excitation of $\varepsilon(t)=\varepsilon_{0} \sin (\omega t)$ was applied to the viscoelastic body, the time lag was generated between stress and strain, and phase angle difference $\delta$ existed. 
Generally, the hysteresis effect of viscoelasticity is manifested by the time lag of strain to stress. Thus, when the phase angle difference of strain lagging behind stress is $\delta$, time lag $t=\delta / \omega$. According to the constitutive equation of Maxwell model, the complex modulus can be obtained using Eq. (2), as follows:

$$
\begin{aligned}
& R^{*}(i \omega)=\frac{\sigma^{*}(t)}{\varepsilon^{*}(t)}=\frac{\sigma_{0}}{\varepsilon_{0}} \cdot \mathrm{e}^{i \sigma}= \\
& =\left|R^{*}\right|(\cos \delta+i \cdot \sin \delta)=R_{1}(\omega)+i R_{2}(\omega)
\end{aligned}
$$

where $\left|R^{*}\right|$ is the modulus of complex modulus $R^{*}(i \omega)$, and its expression is shown in Eq. (3), as follows:

$\left|R^{*}\right|=\frac{\sigma_{0}}{\varepsilon_{0}}=\sqrt{R_{1}^{2}+R_{2}^{2}}$

$\Delta$ is the phase angle difference between oscillation excitation and response $(0<\delta<\pi / 2)$, and the following Eq. (4) holds:

$\tan \delta=\frac{R_{2}}{R_{1}}$

The actual component $R_{1}$ of complex modulus $R^{*}(i \omega)$ is dynamic elasticity modulus or storage modulus, and it reflects storage and release of elastic energy and characterizes elastic property. Imaginary part $k$ viscosity loss modulus or energy dissipation modulus, ? it reflects loss and dissipation of viscous energy at characterizes viscous property of the materi , tan is los. tangent or loss factor. Greater elastic art $R_{1} ;$ dicates greater elasticity modulus and closer ateria Greater viscous part $R_{2}$ indicates malle cosity and closer material to fluid. In $t^{\prime}$ compress test, the complex modulus is expresse in $\mathrm{L}$ (5). In the var test, the complex modulus is eypressed in (6), as follows:

$E^{*}(i \omega)=E_{1}+E_{2}$

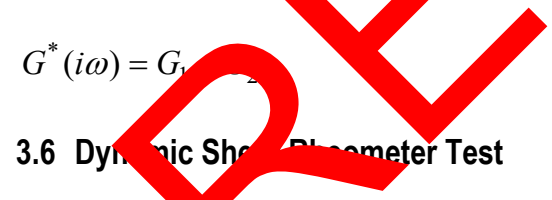

The dyna ic shear rheometer (DSR) test can be used to determine co lex shear modulus and phase angle of the asphalt to characterize its viscoelastic property. The complex shear modulus is shown in Eq. (7), and the phase angle $\delta$ is the phase angle difference between oscillation excitation and response. Since load is applied in the test, its working principle and stress-strain curve are presented in Fig. 1. The complex shear modulus consists of two parts, namely, dynamic elasticity modulus or storage modulus and viscosity loss modulus or dissipation modulus. Within the interval of linear viscoelasticity, greater elasticity modulus indicates a stronger elastic property of the material. Viscosity loss modulus characterizes viscosity loss modulus during the asphalt deformation process, and greater $G_{2}$ indicates greater viscosity loss of the asphalt material under stress action. Fig. 4 presents DSR test principle and stress-strain curve.

$$
G^{*}=\tau_{\max } / \gamma_{\max }
$$

\begin{tabular}{|c|c|c|c|c|c|}
\hline Sample & $\begin{array}{l}\text { Terminal dynamic } \\
\text { maximum load / kg }\end{array}$ & $\begin{array}{l}\text { Temperature rise at } \\
\text { bottom } /{ }^{\circ} \mathrm{C}\end{array}$ & $\begin{array}{c}\text { Internal } \\
\text { temperature rise / } \\
{ }^{\circ} \mathrm{C}\end{array}$ & Static load / kg & $\begin{array}{c}\text { Terminal dynamic } \\
\text { maximum load / } \\
\mathrm{kg}\end{array}$ \\
\hline HMB-W & 0.8 & 6.1 & 6.5 & 2.1 & 0.4 \\
\hline SBS modified asphalt & 0.9 & 6.3 & 7.6 & 1.2 & 0.5 \\
\hline HMB-W + mineral powder & 1.6 & 5.6 & 7.1 & 3.3 & 0.8 \\
\hline SBS modified asphalt + mineral powder & 1.3 & 5.9 & 8.4 & 1.3 & 0.6 \\
\hline
\end{tabular}

Tab. 2 shows that the temperature rise at the bottom of the low rolling resistance modified asphalt was $6.1{ }^{\circ} \mathrm{C}$, which was lower than that of SBS modified asphalt $\left(6.3^{\circ} \mathrm{C}\right)$. In addition, the critical internal temperature rise at $6.5^{\circ} \mathrm{C}$ of the low rolling resistance modified asphalt was much lower than that of SBS modified asphalt $\left(7.6^{\circ} \mathrm{C}\right)$, 
with reduction amplitude reaching $14.4 \%$. In addition, compared with SBS modified asphalt mastic, the temperature rise at the bottom of the mastic prepared by mixing the low rolling resistance modified asphalt and mineral powder was reduced by $0.3{ }^{\circ} \mathrm{C}$. Moreover, the reduction amplitude of the internal temperature rise was larger, at $1.3{ }^{\circ} \mathrm{C}$, which was $15.5 \%$ of that of SBS modified asphalt. Evidently, by combining the four samples generated by the heat quantity, the low rolling resistance modified asphalt was small, and the energy consumed by internal friction was low when deformation occurred. Thus energy loss was effectively reduced, thereby verifying the low phase angle phenomenon in the previous section, the reason for small phase angle could be explained from macroperspective.

\subsection{Rolling Resistance Test}

The rolling resistance test of the two samples was implemented, and the test results are shown in Fig. 5 to Fig. 7.

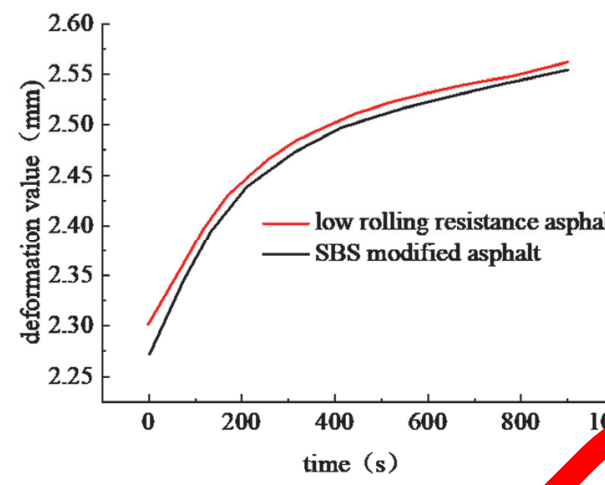

Figure 5 Deformation change in two asphalt rolling resirn mode

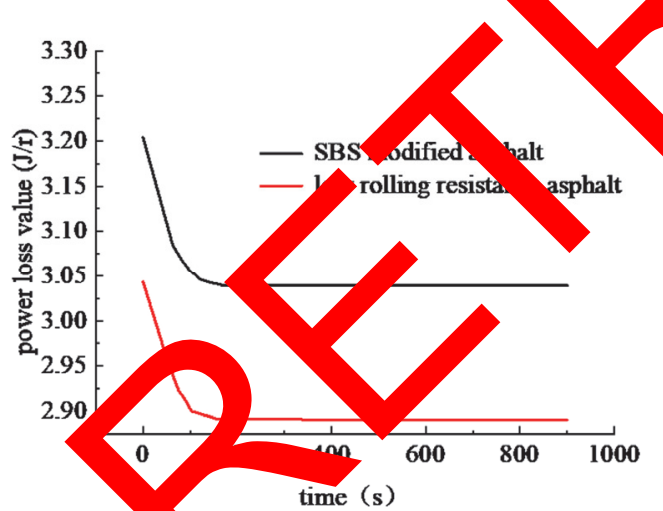

Figure 6 Power lo change in two asphalt rolling resistance models

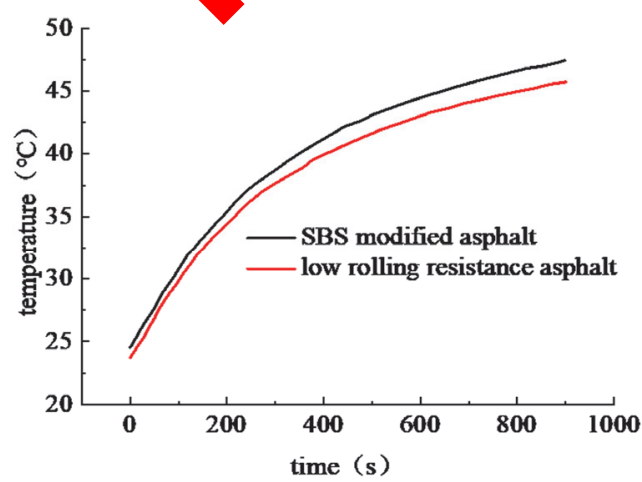

Figure 7 Temperature change in two asphalt rolling resistance models
As shown in Fig. 5, the deformation values of the rolling resistance models of the two samples were consistent. The increased amplitude in deformation value was initially enlarged and then slowed down with time. When the deformation value was $2.5 \mathrm{~mm}$, the deformation would no longer change and reach critical values.

Fig. 6 shows that the power loss values of the rolling resistance models of both samples gradually declined with time. After $100 \mathrm{~s}$, their loss values would no longer decrease. However, they would tend to be stable, following the inflection point. The power loss of the low rolling resistance modified asphalt was smaller than that of SBS modified asphalt, and its initial value, inflection point and final value were smaller than those of SBS modified asphalt. In addition, its power loss ns reduced by approximately $5 \%$. Thus, the en gy loss of effectively reduced.

Fig. 7 shows that th temp tures of he rolling resistance models of th wo sampla tart rising from the initial value $25^{\circ}$ sheir ri $\mathrm{Ag}$ trenc ere consistent. However, the final to ver are of the rolling resistance model of the lo rolling sistance codified asphalt was smaller thar of SBS d asphalt after $900 \mathrm{~s}$, indicating nat temperatu. change amplitude was smaller than that of SS modified asphalt mode during the roll cos. In the fric al process, the heat generated on it model surface was also small. According to the to pperature va after the test, the heat quantity generated in e low roll g resistance modified asphalt model was low by $3.7 \%$ ). This finding corresponds to the internal heatin ing test data. Therefore, the heat generation rate could be decreased, and energy loss could be effectively reduced.

\subsection{Temperature Sensitivity Test 4.3.1 Stress Scanning}

Fig. 8 indicates the following:

1) At test temperature of $60{ }^{\circ} \mathrm{C}$, the complex shear modulus $G^{*}$ of the two asphalts attenuated with a continuous increase in stress. However, they did not go through rapid attenuation within the scope of vibration stress, that is $0-1000 \mathrm{~Pa}$. Therefore, approximately, $G^{*}$ did not present stress-dependent change. Furthermore, the interval of linear viscoelasticity was the scope of vibration stress, namely $0-1000 \mathrm{~Pa}$.

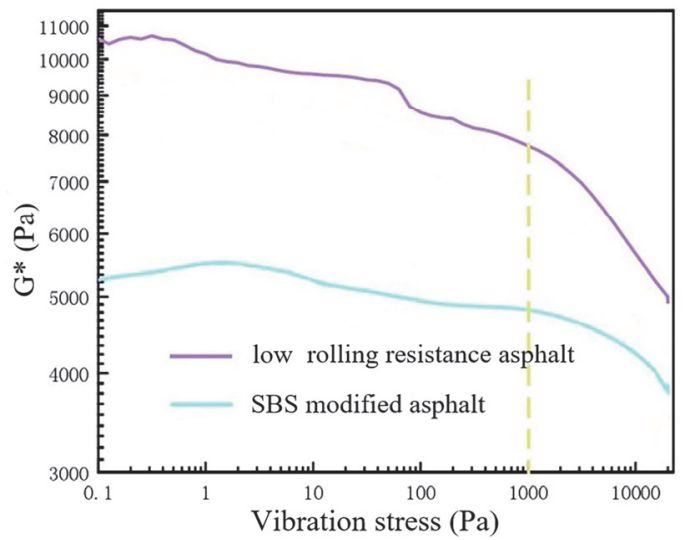

Figure 8 Stress scanning curves of two asphalt types 
2) Under the same stress level, the complex shear modulus $G^{*}$ of the low rolling resistance modified asphalt was evidently higher than that of SBS modified asphalt. Linear viscoelasticity theory in 3.1 indicates that the complex shear modulus $G^{*}$ consisted of two parts, namely, dynamic elasticity modulus (storage modulus) and viscous loss modulus (dissipation modulus). Therefore, dynamic elasticity modulus (storage modulus) and viscous loss modulus (dissipation modulus) should be further investigated to compare the viscoelastic properties of these asphalts.

\subsubsection{Temperature Scanning}

The temperature scanning test of the low rolling resistance modified asphalt and SBS modified asphalt was carried out with a dynamic shear rheometer, the temperature scanning scope was $58-75^{\circ} \mathrm{C}$, the heating rate was $1{ }^{\circ} \mathrm{C} / \mathrm{min}$, and the scanning frequency was $10 \mathrm{rad} / \mathrm{s}$. The temperature-dependent changes in dynamic elasticity modulus (storage modulus) $G_{1}$ and viscous loss modulus (dissipation modulus) $G_{2}$ are shown in Fig. 9 and Fig. 10 . The test results were linearly fitted, as shown in Tab. 3 .

As shown in Fig. 9 and Fig. 10 and Tab. 3:

1) The dynamic elasticity modulus (storage modulus) $G_{1}$ and viscosity loss modulus (dissipation modulus) $G_{2}$ of both asphalts declined as the temperature rose. The linear fitting results analysis of the curves shows that the absolute value of the curve slope of the low rolling resistance modified asphalt was small. This finding manifests thathe sensitivity of the low rolling resistance modified aspha to temperature was smaller than that of SBS modified asph and reflects its stable high-temperature performance.

2) The comparative test results of dy mic modulus (storage modulus) $G_{1}$ and visc aty loss odulus (dissipation modulus) $G_{2}$ of the two a halte same temperature show that the rue of low rolling resistance modified asphalt $y$ larger tha the SBS modified asphalt. This findin ndic that the lo rolling resistance modified aspb had high vnamic elasticity

Table 3 Linear fitting results and correlation coefficients

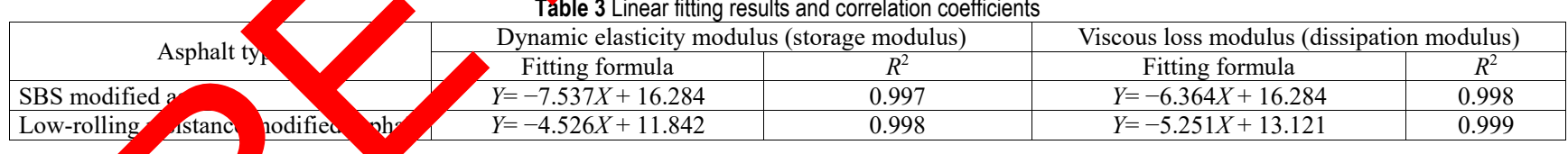

5

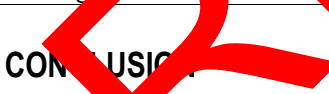

To evalua the performance of low rolling resistance modified asphalt, nternal heat-generating test and rolling resistance test were conducted. Besides, Dynamic shear tests in the form of stress scanning and temperature scanning were carried out for the low rolling resistance modified asphalt and SBS modified asphalt, and their difference in viscoelasticity was comparatively analyzed. The following conclusions could be drawn:

(1) The stress scanning results at the test temperature of $60{ }^{\circ} \mathrm{C}$ showed that both asphalts were within the scope of vibration stress with linear viscoelasticity interval of 0 $1000 \mathrm{~Pa}$. Under the same stress level, the complex shear modulus $G^{*}$ of the low rolling resistance modified asphalt was evidently higher than that of SBS modified asphalt;

(2) The heat generation rate of the low rolling modulus (storage modulus) $G_{1}$ under stress action. Thus, the elastic deformation of the pavement was small; the viscosity loss modulus (dissipation modulus) $G_{2}$ of the low rolling resistance modified asphalt was small, this finding suggests that its viscosity loss was small, viscoelasticity transformation was fast, and strain hysteresis was minor.

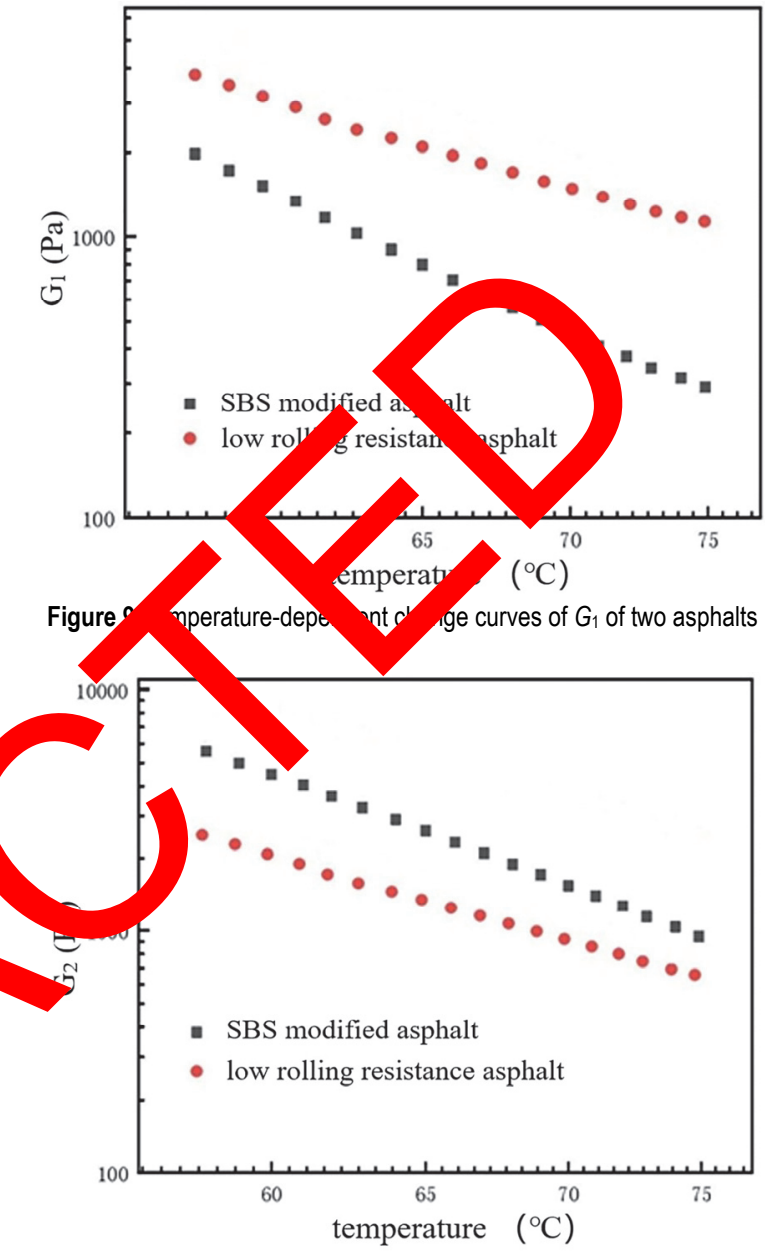

Figure 10 Temperature-dependent change curves of $G_{2}$ of two asphalts resistance modified asphalt was evidently lower than that of the low rolling resistance modified asphalt mastic, and that of the SBS modified asphalt was evidently lower than that of SBS modified asphalt mastic, indicating that the addition of the low rolling resistance modifier could effectively reduce energy consumption. According to the constructed asphalt rolling resistance model, the heat quantity generated was reduced by $3.7 \%$ comparison with that generated in the SBS modified asphalt, the power loss was reduced by $5 \%$, and the low rolling resistance characteristic was evident;

(3) The curve fitting results of the temperature scanning test showed that the temperature sensitivity of the low rolling resistance modified asphalt was low with superior high-temperature stability. Under the same temperature level, the low rolling resistance modified asphalt had large $G_{1}$ and small $G_{2}$. This finding indicates 
that the low rolling resistance modified asphalt not only had high dynamic elasticity modulus, which resulted in small elastic deformation of the pavement, but also small viscosity loss and fast deformation recovery. In addition, the strain hysteresis of the low rolling resistance asphalt pavement could be effectively mitigated.

In summary, the low rolling resistance modified asphalt had excellent low rolling resistance. The temperature scanning test results indicated its small temperature sensitivity and superior high-temperature performance. These findings laid a foundation for further analysing the pavement performance of low rolling resistance modified asphalt mixture under high and lowtemperature conditions. However, as the low rolling resistance asphalt pavement mitigates the rolling resistance between the pavement and tire of a running vehicle, the vehicle may slip due to insufficient frictional force. Hence, the emphasis is placed on the anti-slide performance and waterproof performance of low rolling resistance pavement in the future research to ensure that vehicles can continue running safely with reduced energy consumption.

\section{Acknowledgements}

This work was supported by the Science and Technology Project of Henan Department of Transportation (2020J-2-3), Science and Technology Project of Shaanxi Department of Transportation (No.1732T, No.17-05K, No.19-10K, No.19-28K), and Rising Tech Star Project of Shaanxi Department of Science and Technology (No. 2019KJXX-035).

\section{REFERENCES}

[1] Lv, S., Xia, C., Yang, Q., Guo, S., \& Z ig, J. (2 20). Improvements on high-temperature stabili, veole stiffness of asphalt binder modified wi waste shell powder. Journal of Cleaner Produ , n, 264, 12 5 . https://doi.org/10.1016/j.jclepro.202

[2] Al-Omari, A., Taamneh, M., Khasaw M. A., \& AlHosainat, A. (2018). pect of cru tire rubber, microcrystalline synth wax, and nano sh on asphalt rheology. Road Mat als \& P ment Design, 21(3), 757779. https://doi.org/10. No/14f 029.20181527718

[3] Guolin, W., Zjlong, D., en, L., J', Y., \& Zhijun, W. (2014). Stur on e rela shir etween the grounding character cs and ling rest e of radial tire. Journal of mechar lengin $50(16), 186-192$. https://doi.o 10 J01/JMIE.cor4.16.186

[4] Jing, R., Và ri, A., Liu, X., Scarpas, A., \& Erkens, S. (2019). Labora and Field Aging Effect on Bitumen Chemistry and Keology in Porous Asphalt Mixture. Transportation Research Record, 2673(3), 365-374. https://doi.org/10.1177/0361198119833362

[5] Rahman, M. S., Podolsky, J. H., Williams, R. C., \& Scholz, T. (2018). A study of top-down cracking in the state of Oregon. Road materials and pavement design, 19(7-8), 1771-1795. https://doi.org/10.1080/14680629.2017.1345782

[6] Zhou, M. Y., Li, F. Z., Yang, H. B., \& Zhang, L. Q. (2020). Tire rolling and heat generation based on nonlinear viscoelastic constitutive model. Polymer materials science and engineering, 36(3), 73-78.

[7] Pahlavan, F., Hung, A., \& Fini, E. H. (2018). Evolution of molecular packing and rheology in asphalt binder during rejuvenation. Fuel, 222(JUN.15), 457-464. https://doi.org/10.1016/j.fuel.2018.02.184
[8] Giustozzi, F., Mansour, K., Patti, F., Pannirselvam, M., \& Fiori, F. (2018). Shear rheology and microstructure of mining material-bitumen composites as filler replacement in asphalt mastics. Construction and Building Materials, 171(MAY20), 726-735. https://doi.org/10.1016/j.conbuildmat.2018.03.190

[9] Laclair, T. J. \& Truemner, R. (2012). Modeling of Fuel Consumption for Heavy-Duty Trucks and the Impact of Tire Rolling Resistance. Sae Commercial Vehicle Engineering Conference. https://doi.org/10.4271/2005-01-3550

[10] Mammetti, M., Gallegos, D., Freixas, A., \& Muñoz, J. (2013). The influence of rolling resistance on fuel consumption in heavy-duty vehicles. SAE Technical Paper Series, 1343(1), 1-13. https://doi.org/10.4271/2013-01-1343

[11] Peide, C., Yue, X., Mingjing, F., Zongwu, C., Mingwei, Y., \& Mingliang, L. (2018). Residual fotioue properties of asphalt pavement after long-tern reld su ice. Materials, 11(6), 892. https://doi.org/10.339r a11060892

[12] Martin, J., Rudolf, H., Otaka V., Dusan, B Jiri, S., \& Ludovit, Z. (2015). R' $\mathrm{R}^{\prime}$ logy convent hal asphalt modified with SBS, F' aloy and por hosp ic acid. Fuel Processing Techno sy, 140, 2-179. https://doi.org/10,10, fupror 015.09 .002

[13] Katarína, Z. araj, Mlvia, K \& Matej, B. (2016). Rheology eformation Prop es and Fatigue of the Surface op t Mixtures. A dia Engineering, 153, 909914. haps://doi.o 10.1016/j.proeng.2016.08.224

[14] Wano Z. R., Gao, F., Tao, Z., \& Fan, G. M. (2019). Study in envrgy loss caus by tire runout under uneven road surface. Mechanical design and manufacturing engineering, $48(2), 47-5$

Hernandez, A., Al-Qadi, I L., \& Ozer, H. (2017). Baseline 1'ing re ance for tires' on-road fuel efficiency using fimm ment modeling. The international journal of navement engineering, 18(5-6), 424-432.

In, o. //doi.org/10.1080/10298436.2015.1095298

[16] Bi, F. (2019). Characterization and mechanism of low rolling resistance modified asphalt. Master's Thesis, Shandong Jianzhu University, Jinan, China.

[17] Espinoza-Luque, A. F., Al-Qadi, I. L., Ozer, H., \& Pettinari, M. (2019). Laboratory Characterization of Low-Rolling Resistance Danish Stone-Matrix Asphalt. Journal of Transportation Engineering Part B Pavements, 145(1), 1-9. https://doi.org/10.1080/10298436.2015.1095298

[18] Zhangy, H. M., Ding, Q. Y., Liu, P., \& Jiao, W. X. (2019). Optimization of tread compound formula for low rolling resistance passenger car tire. Tire industry, 39 (1), 40-44.

[19] Li, H., Wang, W., Li, W., Taoum, A., \& Guo, P. (2019). Replacement of Limestone with Volcanic Stone in Asphalt Mastic Used for Road Pavement. Arabian Journal for Science and Engineering, 44, 8629-8644. https://doi.org/10.1007/s13369-019-04028-w

[20] Li, H., Liu, G., Dong, B., Zhao, G., \& Sheng, Y. (2019). Research on the development and regeneration performance of asphalt rejuvenator based on the mixed waste engine oil and waste cooking oil. International Journal of Pavement Research and Technology, 12(3), 336-346. https://doi.org/10.1007/s42947-019-0040-1

[21] Ma, F., Zhang, Y., Fu, Z., \& Feng, Q. (2019). Gradation optimization of new rubber powder and anti rut compound modified asphalt mixture. Journal of Wuhan University (Engineering Edition), 52 (8), 687-693 + 702.

[22] Wang, L. Z., Chang, Z. H., Zheng, G. S., Wang, P., \& Zhang T. (2019). Study on rheological properties and microstructure of low damping modified asphalt. Journal of Shandong Jianzhu University, 34(3), 1-8.

[23] Biligiri, K. P. (2013). Effect of pavement materials' damping propertiesontyre/road noise characteristics. Construction and BuIding Materials, 49, 223-232. https://doi.org/10.1016/j.conbuildmat.2013.08.016 
[24] Biligiri, K. P., \& Way, G. B. (2014). Noise-damping character is tics of different pavement surface wearing courses. Road Materials and Pavement Design, 15(4), 925941. https://doi.org/10.1080/14680629.2014.902768

[25] Zhang, T. (2019).Study on rheological properties of low damping modified asphalt. Master's Thesis, Shandong Jianzhu University, Jinan, China.

\section{Contact information:}

Haibin LI, PhD

(Corresponding author)

School of Architecture and Civil Engineering,

Xi'an University of Science and Technology,

NO. 58 Yanta North Road, Beilin district, Xi'an, Shaanxi, 710054, China

E-mail: lihaibin1212@126.com

\section{Mingming Zhang}

School of Architecture and Civil Engineering,

Xi'an University of Science and Technology,

NO. 58 Yanta North Road, Beilin district, Xi'an, Shaanxi, 710054, China

E-mail: 20204228117@stu.xust.edu.cn

\section{Wenbo LI}

School of Architecture and Civil Engineering,

Xi'an University of Science and Technology,

NO. 58 Yanta North Road, Beilin district, Xi'an, Shaanxi, 710054, China E-mail: yalwb@qq.com

Yan LI, PhD

Xi'an Highway Research Institute,

NO. 60 Gaoxin 6th Road, Gaoxin district, Xi'an, Shaanxi, 710075, China E-mail: yanli@126.com

\section{Qinwei MA, PhD}

Xi'an Highway Research Institute,

NO. 60 Gaoxin 6th Road, Gaoxin district, Xi'an, Shaanxi, 710075, China E-mail: 287314139@qq.com

\section{Guijuan ZHAO, PhD}

School of Architecture and Civil Engineering Xi'an University of Science and Technology, NO. 58 Yanta North Road, Beilin district, Xi'an,

E-mail: guijuanzhao@126.com
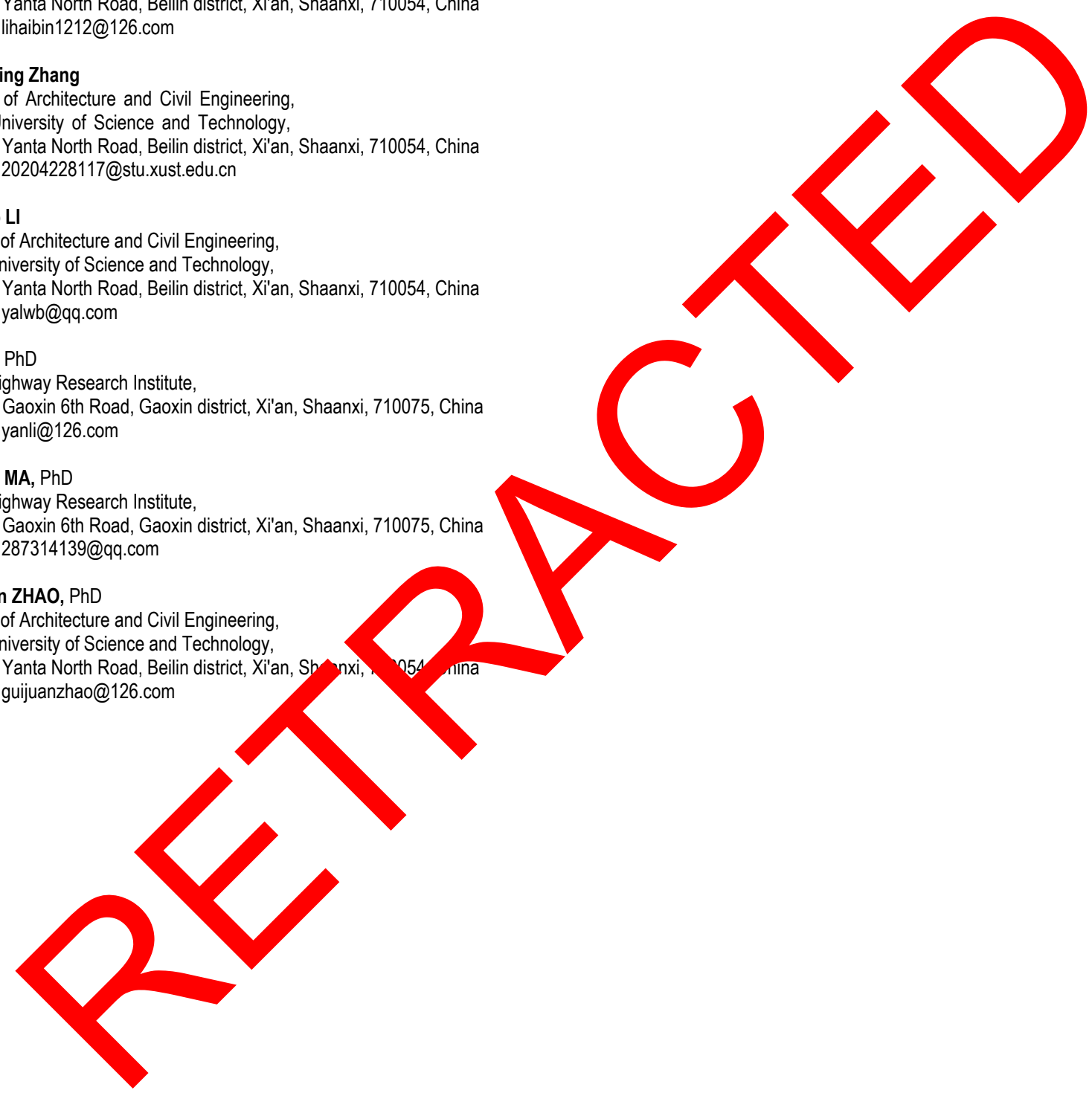